\title{
Safety and efficacy of laparoscopic cholecystectomy during pregnancy: A comparative study between low-pressure and gasless laparoscopy
}

\author{
Alaa El-Ashry, ${ }^{a}$ MD, FRCS; Sabah Abdel Raouf Mohamed, ${ }^{b} M D$
}

a) Department of General Surgery, Ain Shams University, Cairo, Egypt.

b) Department of Anesthesia, Ain Shams University, Cairo, Egypt.

\section{Correspondence:}

Alaa El Ashry, Prince Abd El Aziz Bin Mosaed Hospital, Arar 91421, POBox 934, Saudi Arabia. E.mail:drelashry@yahoo.com

\begin{abstract}
Pregnancy and high parity increase the risk of cholelithiasis and its complications during pregnancy. Laparoscopic cholecystectomy for failed conservative treatment of symptomatic cases during pregnancy is no longer been a contraindication. The potential risk of pneumoperitoneal pressure and $\mathrm{CO} 2$ insufflation triggered the use of modified techniques as gasless and low pressure cholecystectomy for materno-fetal safety.

Patients and methods: Thirteen pregnant patients with indicated cholecystectomy were randomly assigned for either low-pressure laparoscopy (LPL) (6 patients) or gasless laparoscopy (GL) (7 patients). Patients were compared for respiratory and blood gases changes, hemodynamic changes, anesthetic requirements, surgical and early postoperative outcomes and materno-fetal well-being during hospitalization and they were followed up till delivery.

Results: After CO2 insufflation there were significant differences between the 2 groups with increase in the cardiopulmonary parameters namely; PaCO2, PetCO2, peak airway pressure, heart rate and the mean arterial blood pressure and a decrease in $p H$ in the LPL group. The operating time and anesthetic drugs used were significantly more for the GL group. No recorded differences in the postoperative abdominal pain, postoperative nausea and vomiting (PONV) and fetal heart rate changes.

Conclusion: Both low pressure and gasless laparoscopy provide a safe technique for laparoscopic cholecystectomy during pregnancy. However, gasless technique is associated with lower cardiopulmonary effects, despite its longer operating time. In patients with compromised cardiopulmonary function during pregnancy, the gasless technique provides a safer method to avoid the potential adverse effects of pneumoperitoneal pressure and CO2 insufflation.

Key words: Pregnancy - Laparoscopic cholecystectomy - Gasless - Abdominal wall lift Low-pressure cholecystectomy.
\end{abstract}

\section{Introduction:}

The incidence and prevalence of cholelithiasis together with its complications are high in Saudi Arabia. ${ }^{1,2}$ The principle factors are contributed to overweight, early age of menarche, early marriage and high parity. ${ }^{3}$ Repeated pregnancies and multiparity are accepted as risk factors for cholelithiasis. ${ }^{4,5}$ Acute cholecystitis is the second most common non-obestetric emergency during pregnancy, after acute appendicitis. 6,7
Surgical intervention should be delayed until after delivery, unless conservative treatment fails with persistence of symptoms or symptoms recur. ${ }^{8,9}$ Although pregnancy was once considered an absolute contraindication to the performance of laparoscopic procedures, the laparoscopic management of symptomatic cholelithiasis in pregnancy showed better outcomes than open cholecystectomy, with decreased risk of spontaneous abortion and preterm labor. ${ }^{6,10}$ 
The potential risks on the mother and fetus caused by pneumoperitoneum and insufflation of carbon dioxide during conventional laparoscopy, ${ }^{11,12}$ have stimulated the development of alternative approaches to perform laparoscopic cholecystectomy in pregnancy; such as the low-pressure pneumoperitoneal insufflation, ${ }^{13}$ abdominal wall lift with low-pressure pneumoperitoneum ${ }^{14}$ and the use of gasless laparoscopy. ${ }^{15,16}$

Comparative studies between these methods in terms of safety and efficacy during pregnancy have not been published yet.

\section{Aim of the study:}

Is to compare the safety and efficacy of low-pressure versus gasless laparoscopic cholecystectomy for symptomatic cholelithiasis during pregnancy.

\section{Patients and methods:}

This study was carried out at Prince Abd El-Aziz Bin Mosaed hospital, MOH (Saudi Arabia), in the period from December 2006 to February 2009. The study included thirteen patients with symptomatic cholelithiasis during pregnancy who failed conservative management and cholecystectomy was indicated during pregnancy. Exclusion criteria involved those patients with ASA score of III or more, previous upper abdominal operations, choledocholithiasis and obesity $\left(\mathrm{BMI}>30 \mathrm{Kg} / \mathrm{m}^{2}\right)$. All patients were assessed by an obstetrician during hospitalization and cardiotocogram (CTG) was done preoperatively and repeated 1,6 and $12 \mathrm{~h}$ postoperatively. A written informed consent was obtained from each patient included the potential risk of abortion/preterm labor and fetal morbidity/mortality.

General anesthesia was induced with fentanyl $2 \mathrm{ug} / \mathrm{kg}$ and sodium thiopental 3$5 \mathrm{mg} / \mathrm{kg}$ and was maintained using isoflurane $0.6 \%$. Supplemental boluses of fentanyl and atracurium were given as needed. Nitrous oxide was not used. The ventilation settings were $10 \mathrm{breath} / \mathrm{min}$, the inspiratory to expiratory ratio was $1: 2$ and tidal volume (VT) was $8 \mathrm{~mL} / \mathrm{kg}$. No end-expiratory positive pressure was used. The minute ventilation was increased by changing the respiratory rate to keep endtidal $\mathrm{CO}_{2}\left(\mathrm{PetCO}_{2}\right)$ of $32-36 \mathrm{mmHg}$ and $\mathrm{PaCO}_{2}$ of $40-45 \mathrm{mmHg}$.

After the induction of general anaesthesia, patients were randomly allocated to either lowpressure laparoscopy (LPL) group or gasless laparoscopy (GL) group using closed envelopes. For both groups, a bladder catheter and a nasogastric tube were in place during the operation, and were removed at the end of the operation. Monitoring of all patients involved the recording of pulse oximetry $\left(\mathrm{SaO}_{2}\right)$, heart rate, noninvasive blood pressure measurement, $\mathrm{PetCO}_{2}$ and peak airway pressure. A radial arterial line was fixed for blood gases and acid-base analysis. Samples were withdrawn before induction of anesthesia and then every $15 \mathrm{~min}$ intraoperatively with another sample at 3 and $12 \mathrm{~h}$ postoperatively. In order to include complete data for all patients intraoperatively, only the first $45 \mathrm{~min}$ were recorded, starting from the insufflation of $\mathrm{CO}_{2}$ in LPL group or lifting the abdominal wall in GL group.

Laparoscopic cholecystectomy was performed using the standard 4-trocar technique. The first umbilical trocar was inserted using the open technique (Hasson method) and then patients were placed in a $30^{\circ}$ reverse Trendelenburg position and a $10^{\circ}$ left lateral tilt, to displace the gravid uterus from inferior vena cava thereby maintaining venous return. Ephedrine 10mg was given if the systolic blood pressure decreased by more than $20 \%$ of the baseline.

In LPL group, pneumoperitoneal insufflation was kept at $10 \mathrm{mmHg}$ with the insertion of the rest of trocars under vision. In GL group, 2 large towel-clip forceps were fixed to the abdominal wall, one in the midline and the other one at the right hypochondrial area close to the insertion of upper abdominal trocars, which were placed under vision after traction. Traction over these two forceps was achieved by the means of cords hanged over a side bar fixed on each side of the operating table Figure(1). Orthopaedic traction weights were used to achieve the required working space Figure(2). A third towel-clip forceps was applied just above the umbilical port site, upward traction on such forceps is needed only 
at the introduction of the camera, without the need to be fixed to a cord.

Laparoscopic cholecystectomy proceeded in the same manner for both groups. Intraoperative cholangiogram was not done. Suction tube drain was placed at the gallbladder bed for all patients and removed after $24 \mathrm{hs}$. The operation time was calculated from the first skin incision till the last stitch.

Postoperative recordings were performed by a trained nurse, unaware of the method used during operation. The patients were monitored postoperatively for: The occurrence of postoperative nausea and vomiting (PONV), right shoulder pain, intensity of pain (measured by the visual analogue scale (VAS 0-10)) at 2, 6, 12, 18 and $24 \mathrm{~h}$ postoperative, the analgesic requirements (Paracetamol 1 gm i.v for VAS above 5) and paralytic ileus time (calculated in hours from the end of the procedure to the

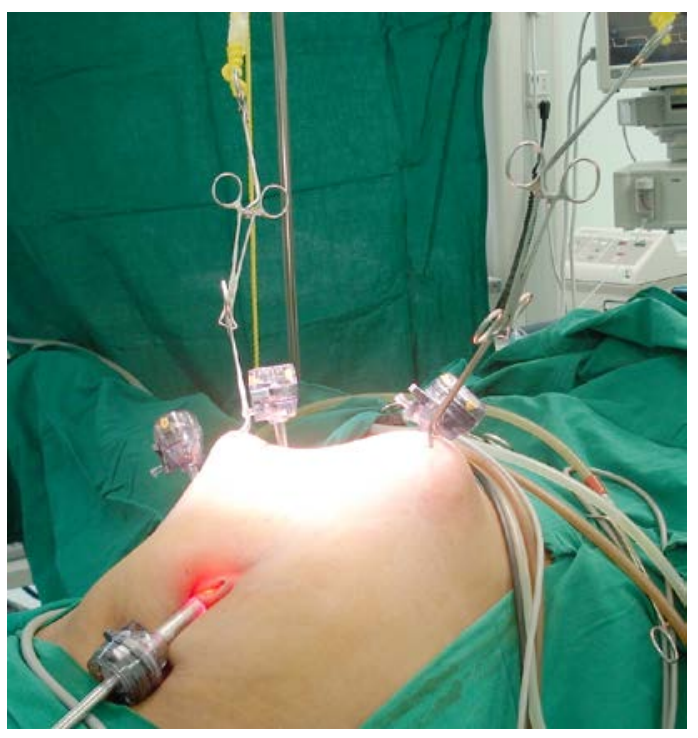

Figure (1): Abdominal wall lifting. ability to pass stool or gas). Patients were reassessed by the obstetrician for materno-fetal well-being and followed-up till delivery.

Respiratory function test performed $24 \mathrm{~h}$ prior to surgery and repeated $48 \mathrm{~h}$ postoperatively including: Forced vital capacity (FVC), forced expiratory volume in 1 second (FEV1) and peak expiratory flow rate.

\section{Statistical analysis:}

The differences of means between the groups were analyzed using $t$-test. The chisquare test, Fisher's exact test and Mann-Whitney $U$-test were used where appropriate. Data were analyzed using SPSS version 8.0.0. A $p$ value of less than 0.05 was considered to represent statistically significant difference between tested groups. Data are expressed as mean $\pm \mathrm{SD}$, number (\%) or median (range).

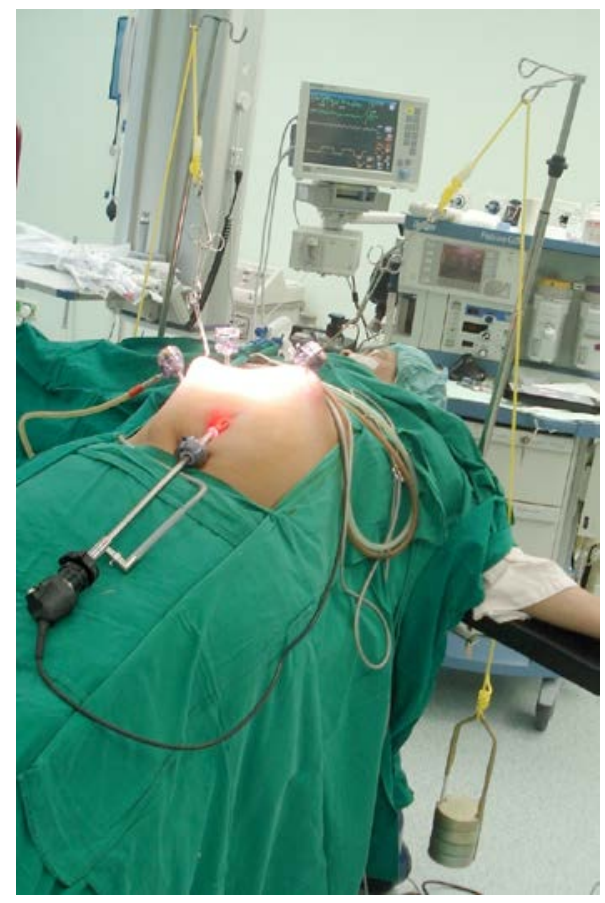

Figure (2): Traction with orthopedic weights. 


\section{Results:}

\section{Demographic data:}

A total of 13 patients were included in the study. Low pressure laparoscopy (LPL) group included 6 patients and gasless laparoscopy (GL) group included 7 patients. Patient characteristics are summarized in Table(1). There appeared to be no significant difference in patient characteristics between the 2 study groups preoperatively.

Respiratory and blood-gas parameters:

The mean values of $\mathrm{PaCO}_{2}, \mathrm{PetCO}_{2}$ and peak airway pressure were significantly higher in the LPL group starting from the $15 \mathrm{~min}$ after insufflation or abdominal wall lifting and continued throughout the intervention till desufflation. In the LPL group, a decrease in $\mathrm{pH}(\mathrm{p}<0.001)$ was noted following $\mathrm{CO}_{2}$ insufflation, which continued till desufflation of gas was completed with significant differences at 30 and $45 \mathrm{~min}$ Table(2). At 3 and $12 \mathrm{~h}$ postoperatively, $\mathrm{pH}$ and $\mathrm{PaCO}_{2}$ showed no significant difference between the groups. At $3 \mathrm{~h}$ postoperatively, $\mathrm{PaCO}_{2}$ values remained above the basal readings and $\mathrm{pH}$ lower than the basal readings in the LPL group and both returned to normal at the $12 \mathrm{~h}$ recording. Respiratory function tests were comparable in the pre- and postoperative period in both groups Table(3).

\section{Hemodynamic parameters:}

The heart rate and mean arterial blood pressure were significantly raised in the LPL group ( $\mathrm{p}<0.001$ ) after $15 \mathrm{~min}$ from abdominal insufflation and remained elevated till complete desufflation of gas Figure(1,2).

\section{Anesthetic parameters:}

Patients in the GL group consumed more fentanyl and atracurium Table(4). The minute volume of ventilation needed to be increased during the first $15 \mathrm{~min}$ of insufflation in the LPL group $(\mathrm{p}<0.001)$ to achieve normoventilation and no changes were required in the GL group Table(5).

\section{Surgical and early postoperative data:}

No statistical difference noticed in comparing the pain using VAS and analgesic requirements at all times ( $p>0.05)$. Table $(6)$ shows the rest of parameters.

\section{Obestetric data:}

Monitoring of fetal heart rate (CTG) did not show significant difference in comparison between the groups pre- and postoperatively $(p=0.68,0.07,0.16,0.17)$. Tocolytic agents were not needed in the study. No preterm labour or abortions were recorded.

Table (1): Patients characteristics.

\begin{tabular}{|l|c|c|c|}
\hline & $\begin{array}{c}\text { LPL group } \\
(\boldsymbol{n}=6)\end{array}$ & $\begin{array}{c}\text { GL group } \\
(n=7)\end{array}$ & p value \\
\hline Age $(\mathrm{y})$ & $27 \pm 4.9$ & $26.6 \pm 4.5$ & 0.87 \\
\hline BMI $\left(\mathrm{Kg} / \mathrm{m}^{2}\right)$ & $28.7 \pm 1.21$ & $28.3 \pm 1.11$ & 0.57 \\
\hline Gravidity & $4(3-5)$ & $3(2-6)$ & 0.38 \\
\hline Gestational age (wk) & $19 \pm 2$ & $17 \pm 4$ & 0.25 \\
\hline
\end{tabular}


Table (2): Respiratory and blood-gas parameters.

\begin{tabular}{|l|c|c|c|}
\hline & $\begin{array}{c}\text { LPL group } \\
(\boldsymbol{n}=\mathbf{6})\end{array}$ & $\begin{array}{c}\text { GL group } \\
(\boldsymbol{n}=7)\end{array}$ & p value \\
\hline Arterial pH: & & & \\
Before induction & $7.43 \pm 0.03$ & $7.43 \pm 0.05$ & 1.00 \\
At 15 min & $7.42 \pm 0.04$ & $7.41 \pm 0.06$ & 0.74 \\
At 30 min & $7.35 \pm 0.06$ & $7.42 \pm 0.03$ & $0.02^{*}$ \\
At 45 min & $7.35 \pm 0.04$ & $7.41 \pm 0.05$ & $0.04^{*}$ \\
3h postop. & $7.40 \pm 0.03$ & $7.41 \pm 0.04$ & 0.63 \\
12h postop. & $7.42 \pm 0.03$ & $7.41 \pm 0.07$ & 0.75 \\
\hline PaCO2 (mmHg): & & & \\
Before induction & $33 \pm 3$ & $34 \pm 2$ & 0.50 \\
At 15 min & $42 \pm 4$ & $36 \pm 3$ & $0.01^{*}$ \\
At 30 min & $43 \pm 1$ & $36 \pm 1$ & $<0.001^{*} *$ \\
At 45 min & $42 \pm 2$ & $36 \pm 2$ & $<0.001^{*}$ \\
3h postop. & $37 \pm 2$ & $33 \pm 7$ & 0.21 \\
12h postop. & $34 \pm 3$ & $33 \pm 1$ & 0.42 \\
\hline PetCO) (mmHg): & & & \\
Before surgery & $30 \pm 2$ & $30 \pm 3$ & 1.00 \\
At 15 min & $35 \pm 3$ & $30 \pm 1$ & $0.002^{*}$ \\
At 30 min & $36 \pm 2$ & $31 \pm 2$ & $<0.001^{* *}$ \\
At 45 min & $36 \pm 3$ & $31 \pm 1$ & $<0.001^{* *}$ \\
\hline Peak airway pressure & & & \\
(cmH2O): & $19.5 \pm 3$ & $18.5 \pm 4$ & 0.63 \\
Before surgery & $25.3 \pm 2$ & $19.6 \pm 3$ & $0.002^{*}$ \\
At 15 min & $28.2 \pm 1$ & $22.1 \pm 4$ & $0.004^{*}$ \\
At 30 min & $27.7 \pm 4$ & $21.5 \pm 2$ & $0.004^{*}$ \\
At 45 min & & & \\
\hline
\end{tabular}

*Statistically significant difference. $\quad * *$ Highly significant difference.

Table (3): Respiratory function test.

\begin{tabular}{|l|c|c|c|}
\hline & $\begin{array}{c}\text { LPL group } \\
(\boldsymbol{n}=6)\end{array}$ & $\begin{array}{c}\text { GL group } \\
(\boldsymbol{n}=7)\end{array}$ & p value \\
\hline Preoperative: & & & \\
Forced vital capacity (L) & $2.53 \pm 0.81$ & $2.48 \pm 0.87$ & 0.92 \\
Forced expiratory volume in 1 sec (L) & $2.66 \pm 0.89$ & $2.82 \pm 1.31$ & 0.81 \\
Peak expiratory flow rate (mL/sec) & $6.72 \pm 1.22$ & $6.34 \pm 1.63$ & 0.65 \\
Postoperative: & & & \\
Forced vital capacity (L) & $2.47 \pm 1.10$ & $2.37 \pm 0.97$ & 0.86 \\
Forced expiratory volume in 1 sec (L) & $2.45 \pm 0.76$ & $2.60 \pm 0.86$ & 0.75 \\
Peak expiratory flow rate (mL/sec) & $6.28 \pm 2.14$ & $6.11 \pm 1.75$ & 0.88 \\
\hline
\end{tabular}


Table (4): Anesthetic requirements.

\begin{tabular}{|l|c|c|c|}
\hline & $\begin{array}{c}\text { LPL group } \\
(\mathbf{n = 6 )}\end{array}$ & $\begin{array}{c}\text { GL group } \\
(\boldsymbol{n}=7)\end{array}$ & p value \\
\hline Isoflurane concentration (\%) & $1.3 \pm 0.1$ & $1.2 \pm 0.2$ & 0.29 \\
\hline Fentanyl (ug) & $125 \pm 15$ & $155 \pm 18$ & $0.01 *$ \\
\hline Atracurium (mg) & $50 \pm 4$ & $60 \pm 3$ & $<0.001 * *$ \\
\hline
\end{tabular}

*Statistically significant difference. $\quad * *$ Highly significant difference.

Table (5): Ventilatory parameters.

\begin{tabular}{|l|c|c|c|}
\hline & $\begin{array}{c}\text { LPL group } \\
(\mathbf{n}=6)\end{array}$ & $\begin{array}{c}\text { GL group } \\
(\boldsymbol{n}=7)\end{array}$ & p value \\
\hline $\begin{array}{l}\text { Minute ventilation } \\
(\mathrm{L} / \mathrm{min})\end{array}$ & $8 \pm 2$ & $5 \pm 1$ & $0.005^{*}$ \\
\hline $\begin{array}{l}\text { Peak inspiratory pressure } \\
(\mathrm{cmH} 2 \mathrm{O})\end{array}$ & $28 \pm 3$ & $21 \pm 2$ & $<0.001^{* *}$ \\
\hline
\end{tabular}

*Statistically significant difference.

**Highly significant difference.

Table (6): Surgical \& postoperative data.

\begin{tabular}{|l|c|c|c|}
\hline & $\begin{array}{c}\text { LPL group } \\
(\mathbf{n = 6})\end{array}$ & $\begin{array}{c}\text { GL group } \\
(\mathbf{n}=7)\end{array}$ & p value \\
\hline Operative time (min) & $62.2 \pm 8.49$ & $72.3 \pm 6.95$ & $0.04^{*}$ \\
\hline Conversion to open & 0 & 0 & 0 \\
\hline Postop. Ileus (h) & $15 \pm 3.5$ & $16 \pm 2.6$ & 0.57 \\
\hline PONV & $2(33)$ & $1(14)$ & 1.00 \\
\hline Right shoulder pain & $4(67)$ & $2(29)$ & 0.29 \\
\hline
\end{tabular}

*Statistically significant difference.

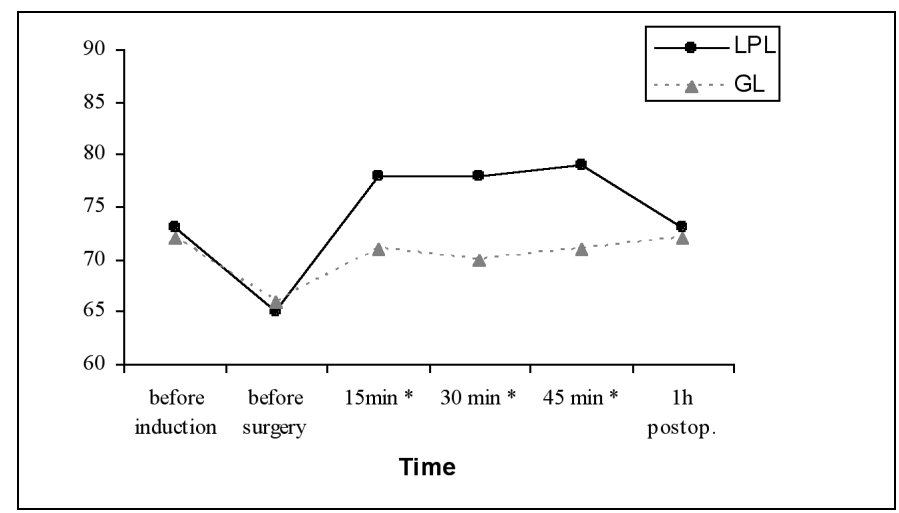

Figure (1): Mean values of heart rate

*Highly significant differences 


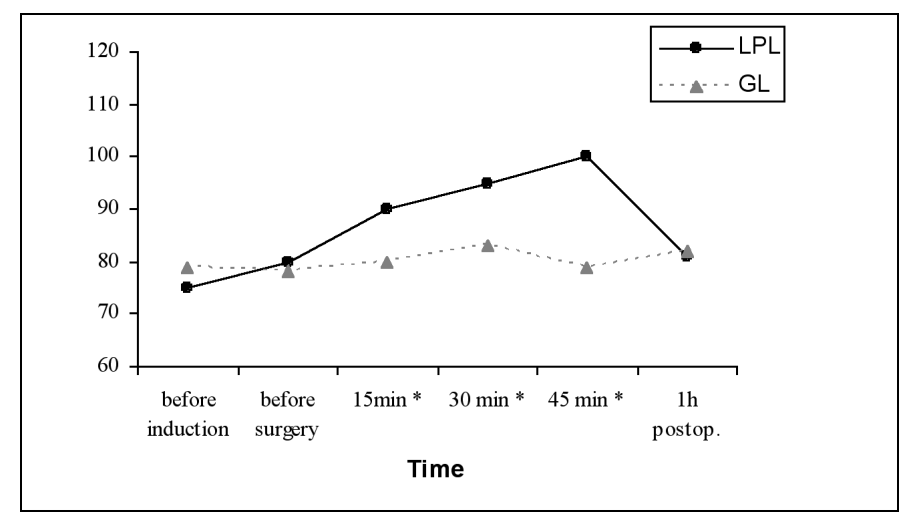

Figure (2): Mean values of the mean arterial blood pressure. *Highly significant differences.

\section{Discussion:}

Being a referral hospital for the northern area of Saudi Arabia, where complications of cholelithiasis during pregnancy are frequently met, gave us the chance to conduct this prospective study on such population group, comparing the outcomes between two reported methods for laparoscopic cholecystectomy during pregnancy.

Pregnant women develop a restrictive pulmonary physiology owing to an enlarged uterus. They are more prone to develop hypoxemia and hypocapnia secondary to an increase in minute ventilation and $\mathrm{O}_{2}$ consumption, increase in peak airway pressure and decreased thoracic cavity compliance. ${ }^{17}$ In accordance with other investigators, ${ }^{18,19}$ we found a significant differences in $\mathrm{PetCO}_{2}$, $\mathrm{PaCO}_{2}$, peak airway pressure and $\mathrm{pH}$ values between abdominal wall lift group and pneumoperitoneal group despite the adjustment of minute ventilation volume. The use of $\mathrm{CO}_{2}$ pneumoperitoneum, even with a very low pressure of $5 \mathrm{mmHg},{ }^{19,20}$ is also associated with a significant difference in $\mathrm{PCO}_{2}$ and $\mathrm{pH}$ from the base line values. This is in agreement with others too, ${ }^{21}$ who showed that, the increase of $\mathrm{PCO}_{2}$ is not linearly related to the intraabdominal pressure of $\mathrm{CO}_{2}$ pneumoperitoneum. It is suggested that, peritoneal absorption area is an important factor to determine the rate of $\mathrm{CO}_{2}$ absorption from the peritoneal cavity 21,22 and hence its consequences. Putting in mind that the fetus is more acidemic than the mother ${ }^{11,12}$ and to ward-off these consequences, one should seek a completely gasless technique rather than the use of abdominal wall lift plus low-pressure $\mathrm{CO}_{2}$ pneumoperitoneum.
We have found a significant increase in heart rate and mean arterial blood pressure values after insufflation and remained high throughout the procedure till desufflation. Similar results were reported by Lindgren et al. ${ }^{23}$ and by de Waal et al. ${ }^{20}$ with even lower pressures (2.7 and $5 \mathrm{mmHg}$ respectively). The later suggested that catecholamine release is the cause of such differences. Elevated catecholamine levels have been seen as a response to $\mathrm{CO}_{2}$ pneumoperitoneum as reported by Joris and Lamy. ${ }^{24}$ Similarly, Adresson et al. ${ }^{25}$ concluded that abdominal wall lift increased cardiac index while pneumoperitoneum did not. And, cardiac filling pressures and systemic vascular resistance were increased by pneumoperitoneum but unaffected by abdominal wall lift. Furthermore, Cunningham et al. ${ }^{26}$ found that $\mathrm{CO}_{2}$ insufflation increased left ventricular end-systolic wall stress. These effects may be deleterious in patients with compromised cardiac function or having pre-eclampsia.

Different instruments and techniques have been used in order to accomplish the gasless space away from the potential side effects of pneumoperitoneum and the insufflation of $\mathrm{CO}_{2}$ such as: Laparolift ${ }^{\mathrm{TM}}$ and laparofan, ${ }^{27}$ Laparotenser ${ }^{\circledR}$ device, ${ }^{28,29}$ traction on straight metal rods, ${ }^{30}$ traction on Foley's catheter, 31 the use of a semi-loop-shaped abdominal retractor ${ }^{32}$ and the use of towel clips with a ceilingmounted laplift. ${ }^{33}$ Some of these instruments are complex, expensive and are not available in all hospitals; others are tedious to mount and assemble with loss of extra time or need extra stab wounds. We have used a simple abdominal wall traction technique to achieve 
gasless, isobaric laparoscopy by the means of two cords attached to large towel-clip forceps, hanged over a side bar on each side of the operating table Figure(2), where orthopedic weights, readily available in ordinary operating rooms, are applied to achieve the required intra-abdominal working space. Creation of a sufficient space in the abdomen, despite the presence of gravid uterus, was not difficult because the population study were females with most of them of high parity with a soft abdominal wall musculature.

The operating time was longer in GL group $(\mathrm{p}=0.038)$, and this is in accordance with other investigators 18,34 in non-pregnant patients. On the other hand, non-significant difference in the operating time in comparing pneumoperitoneal group to abdominal wall lift group was noticed by Alijani et al., 35 Galizia et al. ${ }^{36}$ and Ortiz-Oshhiro et al. ${ }^{37}$ The later in his comparison, divided the operating time into phase 1 , which is the time employed to create the surgical field and phase 2 , which is the actual operating time. This difference between studies may be explained by the use of different methods to create gasless space from one side and on the other side due to the difference in defining the "start-end" points for time calculation.

In accordance with other investigators $18,27,34$ on non-pregnant patients, we didn't find a significant difference in comparing our 2 groups for the postoperative abdominal pain. Although the occurrence of right shoulder pain was more frequent in LPL group, it doesn't attain statistical significance $(p=0.29)$. However, the reported results of the same investigators regarding shoulder pain are contradictory; while Koivusalo et al. ${ }^{27}$ reported that shoulder pain is more with the pneumoperitoneal group, Vezakis ${ }^{34}$ and Uen et al. ${ }^{18}$ reported the reverse; as the pain was more with traction group. This contradiction may be related to the different degrees of diaphragmatic stretching resulted from excessive upward traction of the abdominal wall according to the instruments used and the technique applied to perform gasless space. Uen et al. ${ }^{18}$ for example, has used 2 curved subcutaneously inserted for traction.

\section{Conclusion:}

Both low pressure and gasless laparoscopic cholecystectomy provide a safe technique in pregnancy for symptomatic cholelithiasis. However, gasless laparoscopy is associated with lower cardiopulmonary effects, despite its longer operating time. In patients with compromised cardiopulmonary function during pregnancy, where cholecystectomy is indicated, the gasless technique provides a safer method to avoid the potential adverse effects of pneumoperitoneal pressure and $\mathrm{CO}_{2}$ insufflation. A larger series is recommended.

\section{References:}

1- Al Sulaimani SH, Alam MK, Sengupta H, Girgis A: Incidence of cholelithiasis in patients attending King Abdulaziz University Hospital. Saudi Med J 1986; 7 : 261-265.

2- Tamimi TM, Wosomu L, Al Khozaim A, Abdul-Ghani A: Increased cholecystectomy rates in Saudi Arabia. Lancet 1990; 336: 1235-1237.

3- Murshid KR: Symptomatic gallstones: A disease of young Saudi women. Saudi J Gastroenterol 1998; 4: 159-62.

4- Scott LD: Gallstone disease and pancreatitis in pregnancy. Gastroenterol Clin North Am 1992; 21: 803-815.

5- Talamini MA: Controversies in laparoscopic cholecystectomy: Contraindications, pregnancy and avoidance of complications. Baillieres Clin Gastroenrol 1993; 7: 881896.

6- Graham G, Baxi L, Tharakan T: Laparoscopic cholecystectomy during pregnancy: A case series and review of literature. Obstet Gynecol Surg 1998; 53: 566-574.

7- Halkic N, Tempia-Caliera AA, Ksontini R, Suter M, Delaloye JF, Vuilleumier H: Laparoscopic management of appendicitis and symptomatic cholelithiasis during pregnancy. Langenbecks Arch Surg 2006; 391: 467-471.

8- Cosenza CA, Saffari B, Jabbour N, Stain SC, Garry D, Parekh D: Surgical management of biliary gallstone disease during pregnancy. Am J Surg 1999; 178: 545-548. 
9- Barone JE, Bears S, Chen S, Tsai J, Russell JC: Outcome study of cholecystectomy during pregnancy. Am J Surg 1999; 177: 232-236.

10-Oelsner G, Stockheim D, Soriano D: Pregnancy outcome after laparoscopy or laparotomy in pregnancy. $J$ Am Assoc Gynecol Laparosc 2003; 10(2): 200-204.

11-Bhavani-Shankar K: Arterial to end-tidal carbon dioxide pressure differences during laparoscopic surgery in pregnancy. Anesthesiology 2000; 93(2): 370-373.

12-Reedy MB: Laparoscopy during pregnancy: A study of five fetal outcome parameters with the use of the Swedish health registry. Am J Obstet Gynecol 1997; 177: 673-679.

13-Sakata Y, Oshima T, Tsutsui M, Fukuda I, Satoh T: Laparoscopic cholecystectomy under general anesthesia for a woman in the 28th week of gestation. Masui 2003; 52(11): 1233-1235.

14-Edelman DS: Alternative laparoscopic technique for cholecystectomy during pregnancy. Surg Endosc 1994; 8(7): 794796.

15-Iafrati MD, Yarnell R, Schwaitzberg SD: Gasless laparoscopic cholecystectomy in pregnancy. J Laparoendosc surg 1995; 5(2): 127-130.

16-Pelosi MA: Gasless laparoscopy under epidural anesthesia during pregnancy. $J$ Am Assoc Gynecol Laparosc 1995; 2(4): S75.

17-Steinbrook RA, Brooks DC, Datta S: Laparoscopic cholecystectomy during pregnancy. Surg Endosc 1996; 10(5): 511515.

18-Uen YH, Chen Y, Kuo CY, Wen KC, Koay LB: Randomized trial of low-pressure carbon CO2-elicited pneumoperitoneum versus abdominal wall lifting for laparoscopic cholecystectomy. J Chin Med Assoc 2007; 70(8): 324-330.

19-Meijer DW, Rademaker BPM, Schlooz S, Bemelman WA, de Wit LT, Bannenberg JG, Stijnen T, Gouma DF: Laparoscopic cholecystectomy using abdominal wall retraction: Hemodynamics and gas exchange, a comparison with conventional pneumoperitoneum. Surg Endosc 1997; 11: 645-649. 20-de Waal EEC, de Vries JW, Kruitwagen CL, Kalkman CJ: The effects of lowpressure $\mathrm{CO} 2$ pneumoperitoneum on cerebral oxygenation and cerebral blood volume in children. Anesth Analg 2002; 94:500-505.

21-Lister DR, Rudston-Brown B, Wariner B, Mc Ewen J, Chan M, Walley KR: Carbon dioxide absorption is not linearly related to intraperitoneal carbon dioxide insufflation pressure in pigs. Anesthesiology 1994; 80: 129-136

22-Mullet CE, Viale JP, Sagnard PE, Miellet CC, Ruynat LG, Counioux HC, Motin JP, Boulez JP: Pulmonary CO2 elimination during surgical procedures using intra- or extraperitoneal CO2 insufflation. Anesth Analg 1993; 76: 622-626.

23-Lindgren L, Koivusalo AM, Kellokumpu I: Conventional pneumoperitoneum compared with abdominal wall lift for laparoscopic cholecystectomy. $\mathrm{Br} J$ anaesthesia 1995; 75: 567-572.

24-Joris L, Lamy M: Neuroendocrine changes during pneumoperitoneum for laparoscopic cholecystectomy. Br J Anaesth 1993; 70: A 33.

25-Andersson L, Linberg G, Bringman S, Ramel S, Anderberg B, OdebergWernerman S: Pneumoperitoneum versus abdominal wall lift: Effects on central haemodynamics and intrathoracic pressure during laparoscopic cholecystectomy. Acta Anaesthesiol Scand 2003; 47(7): 838-846.

26-Cunningham A, Turner J, Rosenbaum S, Rafferty T: Transoesophageal echocardiographic assessment of haemodynamic function during laparoscopic cholecystectomy. $B r J$ anaesthesia 1993; 70: 621-625.

27-Koivusalo AM, Kellokumpu I, Lindgren L: Gasless laparoscopic cholecystectomy: Comparison of postoperative recovery with conventional technique. Br J of Anaesthesia 1996; 77: 576-580.

28-Sesti F, Capobianco F, Capozzolo T, Pietropolli A, Piccione E: Isobaric gasless laparoscopy versus minilaparotomy in uterine myomectomy: A randomized trial. Surg Endosc 2008; 22(4): 917-923. 
29-Sampietro R: Correct use of the gasless LaparoTenser system. Surg Endosc 1999; 13: 316.

30-Nakamura H, Kobori Y, Goseki N, Inoue H, Takeshita K, Endo M, Nakamura T: Fishing-rod-type abdominal wall lifter for gasless laparoscopic surgery. Surg Endosc 1996; 10: 944-946.

31-Abbas M, Nafeh AI, Youssef YF, Helmy AH: A modified home-made abdominal wall lift device for gasless laparoscopic cholecystectomy. Egyptian Journal of Surgery 2005; 24 (1): 22-27.

32-Izumi Y, Kawano T, Iwai T: Development and clinical application of semi-loop-shaped retractor for gasless laparoscopic surgery. Surg Endosc 2003; 17: 1488-1493.

33-Nande AG, Shrikhande SV, Rathod V, Adyanthaya K, Shrikhande VN: Modified technique of gasless laparoscopic cholecystectomy in a developing country: A 5-year experience. Dig Surg 2002; 19: 366-372.

34-Vezakis A, Davides D, Gibson JS, Moore MR, Shah H, Larvin M, Mc Mahon MJ: Randomized comparison between lowpressure laparoscopic cholecystectomy and gasless laparoscopic cholecystectomy. Surg Endosc 1999; 13(9): 890-893.
35-Alijani A, Hanna GB, Cuschieri A: Abdominal wall lift versus positive-pressure capnoperitoneum for laparoscopic cholecystectomy. Randomized controlled trial. Annals of Surgery 2004; 239(3): 388394.

36-Galizia G, Prizio G, Lieto E, Castellano P, Pelosio L, Imperatore V: Hemodynamic and pulmonary changes during open, carbon dioxide pneumoperitoneum and abdominal wall-lifting cholecystectomy. A prospective randomized study. Surg Endosc 2001; 15(5): 477-483.

37-Ortiz-Oshiro E, Mayol J, Aparicio Medrano JC, Rabada Ruiz L, Sanjuan Garcia MA, Alvarez Fdez-Represa J: Gasless laparoscopic cholecystectomy is not more time-consuming. Surg Endosc 2001; 15: 1448-1451. 